\title{
Commentary: The Mustard operation is alive and well in Egypt (and elsewhere)
}

\author{
Tom R. Karl, MS, MD, FRACS
}

\footnotetext{
From the European Journal of Cardio-Thoracic Surgery, European Association of Cardio-Thoracic Surgery House, Madeira Walk, Windsor, UK

Disclosures: Author has nothing to disclose with regard to commercial support.

Received for publication Aug 19, 2019; revisions received Aug 19, 2019; accepted for publication Aug 19, 2019; available ahead of print Nov 1, 2019.

Address for reprints: Tom R. Karl, MS, MD, FRACS, European Journal of Cardio-Thoracic Surgery, European Association of Cardio-Thoracic Surgery House, Madeira Walk, Windsor, SL4 IEU, UK (E-mail: trkarl.aus@ gmail.com).

J Thorac Cardiovasc Surg 2020;159:253

$0022-5223 / \$ 36.00$

Copyright $(2019$ by The American Association for Thoracic Surgery

https://doi.org/10.1016/j.jtcvs.2019.08.131
}

Hosny and colleagues ${ }^{1}$ from the Aswan Heart Center present their extraordinary experience with a modification of the Mustard operation for children with a delayed diagnosis and/or presentation of transposition of the great arteries. The senior author is a highly respected pioneer of arterial switch surgery. The 2-stage arterial switch (left ventricular conditioning by pulmonary artery banding) has proven to be a valuable but extremely complex tool. ${ }^{2}$ Without respect for highly evolved selection criteria (especially age limitation), uniform success remains elusive even in economically advantaged environments. Atrial reconstruction (Mustard or Senning) is, therefore, a better alternative in some situations. The noteworthy components of this paper are 2-fold. First, the surgical results are a tour de force considering the patient characteristics. Second, the authors present a compelling discussion of the role of left ventricular filling impairment in late failure following atrial rearrangements for transposition of the great arteries, with a proposal of specific Mustard modifications that may address this issue. Although the follow-up period is relatively short, the data seem convincing in this large series, even with the limitations acknowledged by the authors. In North America, the Mustard is rarely performed today (except in repair of

\section{References} 241-9.

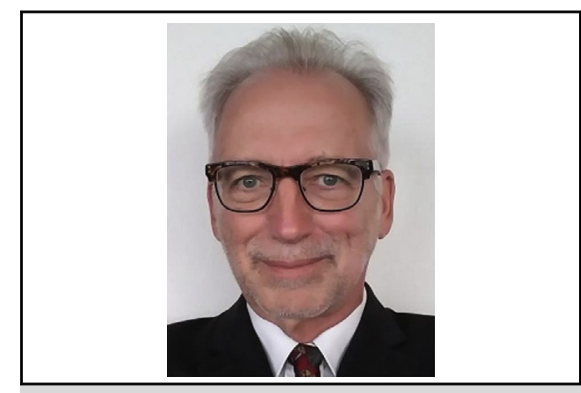

Tom R. Karl, MS, MD, FRACS

Central Message

The Mustard operation (with some novel modifications) has been quite effective for latepresenting patients with transposition (who are unsuitable for 2-stage arterial switch).

See Article page 241 .

complex discordant transposition), and most trainees have limited exposure. In other parts of the world, it remains a critical part of our transposition armamentarium. This paper will have important implications for institutions worldwide regularly treating such patients and also for visiting humanitarian surgical teams.

1. Hosny H, Sedky Y, Romeih S, Simry W, Afifi A, Elsawy A, et al. Revival and modification of the Mustard operation. J Thorac Cardiovasc Surg. 2020;159:

2. Cochrane AD, Karl TR, Mee RBB. Staged conversion to arterial switch for late failure of the systemic right ventricle. Ann Thorac Surg. 1993;56:854-62. 